\title{
PELATIHAN ENGLISH QUESTIONS BAGI PARA PETUGAS PARKIR DI KAWASAN WISATA BUDAYA CIUNG WANARA KARANGKMULYAN
}

\section{TRAINING ENGLISH QUESTIONS TO PARKING ATTENDANTS IN AREA OF CIUNG WANARA CULTURAL TOURISMN OBJECT, KARANGKAMULYAN}

\author{
Dedeh Rohayati", Andi Rustandi, Wawan Tarwana, Indah Nurkhasanah, \\ Ade Rohana
}

\author{
Universitas Galuh, Jalan R.E. Martadinata No. 150 Ciamis, Jawa Barat \\ "Email: dedehrohayati2017@gmail.com \\ (Diterima 11-12-2020; Disetujui 17-02-2021)
}

\begin{abstract}
ABSTRAK
Pentingnya kemampuan komunikasi bahasa Inggris semakin disadari oleh semua pihak, termasuk para petugas parkir di kawasan objek wisata budaya Ciung Wanara, Karangkamulyan. Oleh karena itu, tim pengabdian kepada masyarakat Universitas Galuh melaksanakan pelatihan English Questions, khususnya materi Yes/No Questions dan $5 W+1 H$ Questions. Project-based learning diterapkan dalam program ini dengan berprinsip kepada aspek andragogik. Subjek pengabdian berjumlah 6 orang petugas parkir di area objek wisata budaya Ciung Wanara. Pelatihan English Questions yang meliputi pelafalan dan penggunaannya dengan benar dilakukan selama kurun waktu 7 kali pertemuan. Sumber data pengabdian ini diperoleh melalui observasi dan rekaman video yang dianalisis menggunakan teori pendukung secara deskriptif. Sedangkan penilaian kemampuan English Question menggunakan CEFR. Hasil analisis menunjukan bahwa kemampuan bahasa Inggris yang dimiliki para petugas parkir di kawasan objek wisata budaya Ciung Wanara Karangkamulyan semakin signifikan. Mereka mampu membuat pertanyaan dengan berbagai situasi, apabila ada turis asing datang; diantaranya pertanyaan (1) saat turis datang atau turun dari bus di area parkir; (2) ketika turis hendak mencari restoran; (3) ketika turis keluar dari restoran; (4) saat turis memasuki area Ciung Wanara; (5) ketika turis keluar dari area situs; dan (6) saat turis akan segera melanjutkan perjalanan. Keberhasilan ini diharapkan mampu mendongkrak peningkatan kesan positif objek wisata tersebut dari para pengunjung, terutama turis asing. Dengan demikian, kapasitas para petugas parkir sebagai bagian dari objek wisata budaya Ciung Wanara juga semakin optimal dan para petugas parkir pun dapat meraih keuntungan yang maksimal.
\end{abstract}

Kata kunci: Objek Wisata Budaya Ciung Wanara, petugas parkir, Yes/No Questions, $5 W+1 H$ Questions

\begin{abstract}
All of parties have been aware of the important of English communication ability, including parking attendants in Ciung Wanara Tourismn Object, Karangkamulyan. Therefore, the community service of Universitas Galuh provides the parking attendants the training of English questions skill focusing on Yes/ No Questions dan $5 W+1 H$ Questions. The project-based learning method is applied in this program which is based on andragogical learning principal. They are six parking attendants involving in this community sevice working in the area of Ciung Wanara Cultural Tourismn Object. They are also given the material of Yes/ No Questions and $5 W+1 H$ Questions for about 7 meetings. Furthermore, they are trained to pronounce and communicate properly at the time they do their job. The data consisting of the observation and video recording are analyzed by using theory supported this program descriptively. The performance is scored by using CEFR. The results shows that English communication ability of parking attendant is significantly increase. For example, parking attendants may ask for questions to the torurist who are getting off the bus, looking for restaurant, exiting from restaurant, entering the Ciung Wanara area and exiting from there, and intending to continue the trip. Hopefully, the success can trigger the increase of positive impression from the visitors, especially from the foreign tourist. Thus, not only is the capacity of parking attendants as a front liner of CuingWanara Cultural Tourism Object optimally achieved, but also their profit volume obtained.
\end{abstract}

Keywords: Ciung Wanara Cultural Tourismn Object, parking attendants, Yes/No Questions, $5 W+1 H$ Questions 
Pelatihan English Questions Bagi Para Petugas Parkir di Kawasan Wisata Budaya Ciung Wanara Karangkmulyan

Dedeh Rohayati, Andi Rustandi, Wawan Tarwana, Indah Nurkhasanah, Ade Rohana

\section{PENDAHULUAN}

Peran dan keberadaan para petugas parkir di setiap area parkir sangat penting. Petugas parkir membantu mengelola area parkir sekaligus membantu mengatur arus keluar masuk kendaraan bermotor yang akan memasuki sebuah area, termasuk objek wisata budaya Ciung Wanara yang terletak di Desa Karangkamulyan, Kecamatan Cijeungjing, Kabupaten Ciamis. Ini selaras dengan tugasnya seperti yang termaktub dalam Perda No. 13 Kabupaten Bandung 2013, yakni “Petugas Parkir/Juru Parkir adalah petugas yang diberi tugas mengatur penempatan kendaraan yang diparkir" (https://peraturan.bpk.go.id/Home/Details/26995).

Saat melaksanakan tugasnya, para petugas parkir tidak saja selalu berhadapan dengan turis domestik, akan tetapi, mereka juga harus mampu dan siap berhadapan dengan turis asing. Mereka juga percaya bahwa turis asing akan selalu datang ke area tersebut sehingga menambah kesadaran akan pentingnya penguasaan komunikasi bahasa Inggris. Untuk meningkatkan kapasitasnya sebagai bagian dari objek wisata budaya Ciung Wanara tersebut, mereka melakukan berbagai upaya untuk melayani sebaik mungkin turis asing walaupun dengan kemampuan yang terbatas.

Berdasarkan informasi yang diperoleh dari $\mathrm{Pa}$ Undang, salah seorang petugas parkir senior, sebelum pelaksanaan pengabdian, mereka sering menemui kendala saat berhadapan dengan pengunjung dari mancanegara. Mereka menganggap kemampuan Bahasa Inggris yang dimiliki masih "balelol” (gagap) dan belum menguasai ungkapan Bahasa Inggris transaksional, yakni meminta dan memberi barang atau jasa (Eggins, 2004). Selain faktor usia (para petugas parkir adalah pembelajar dewasa), hal ini sebagai akibat dari kurangnya edukasi di bidang komunikasi Bahasa Inggris. Adapun pelatihan bahasa Inggris sebelumnya (masih di kawasan Wisata budaya Ciung Wanara) diterapkan kepada para pelaku pemasaran kelapa muda dan pelaku pemasaran produk pertanian secara umum yang tergabung dalam Kawargin Adat (Rohayati, dkk., 2019).

Mengingat hal tersebut di atas, pelatihan bahasa Inggris sangat diperlukan bagi para petugas parkir di daerah objek wisata budaya Ciung Wanara Karangkamulyan dengan mempertimbangkan aspek andragogik dan motivasi (Knowles, 2005; Brown, 2007). Pelatihan yang dilakukan lebih difokuskan kepada aspek keahlian bahasa (language skill), khususnya kemampuan berbicara (speaking). Jenis kemampuan berbicara (speaking) nampaknya akan sangat bermanfaat bagi para petugas parkir di daerah objek wisata budaya tersebut untuk dapat berkomunikasi dengan wisatawan mancanegara. Terlebih mengenai English Questions yang terdiri atas: 1) Kalimat tanya Bahasa Inggris jenis Yes/No 
Questions, dan 2) Kalimat tanya Bahasa Inggris menggunakan kata tanya $(5 \mathrm{~W}+1 \mathrm{H}$ Questions).

Materi English Questions ini harus disesuaikan dengan bidang pekerjaannya karena saat di area parkir mereka akan mengungkapkan beberapa pertanyaan seperti 1) Apakah anda bisa berbicara Bahasa Inggris?; 2) Busnya/mobilnya yang mana?; 3) Apakah busnya/ mobilnya yang ini?; Kemanakah tujuan anda selanjutnya?; dst. Hal ini sejalan dengan apa yang dikemukakan oleh Hutchinson \& Waters (1987) dan Dudley-Evan \& St. Jhon (1998) mengenai pembelajaran yang menekankan kepada kebutuhan pembelajar itu sendiri.

Hasil kegiatan ini diharapkan dapat membantu memotivasi para petugas parkir untuk memiliki keterampilann menggunakan English Questions. Sehingga akan semakin bersemangat dalam melakukan tugasnya dan akan dapat meningkatkan kapasitasnya sebagai bagian dari obek wisata budaya Ciung Wanara Karangkamulyan. Selain itu, kegiatan ini sangat berguna karena menitikberatkan kepada intensifikasi dan ekstensifikasi kegiatan pengabdian kepada masyarakat berbasis disiplin keilmuan dan keunikan lokal. Sehingga tujuan pengabdian kepada masyarakat ini adalah sebagai berikut: 1) Mengetahui pelaksanaan pembelajaran yang tepat bagi khalayak sasaran seperti para petugas parkir supaya memiliki kemauan dan kemampuan komunikasi bahasa Inggris menggunakan English Questions, dan 2) Mengetahui bentuk kegiatan pembelajaran yang optimal, sehingga dengan fasilitas yang terbatas semua khalayak sasaran yang meminati pembelajaran bahasa Inggris tersebut, bisa memahami dasar-dasar berbicara bahasa Inggris, khususnya menggunakan English Questions, sehingga mereka bisa mengembangkannya secara mandiri atau kelompok.

\section{BAHAN DAN METODE}

Kegiatan pengabdian kepada masyarakat ini berlangsng selama 1 bulan dimulai dari tanggal 26 Juni sampai 27 Juli tahun 2020 di era New Normal Pandemic Covid-19. Pelaksanaan pengabdian diawali dengan diskusi dan pemberian motivasi pada hari Jumat, 26 Juni 2020, dan pada hari Sabtu, 27 Juni 2020. Lima pertemuan selanjutnya adalah pelatihan Bahasa Inggris yang dilakukan setiap hari Senin mulai tanggal 29 Juni 2020 dan berakhir di hari Senin tanggal 27 Juli 2020.

Sasaran pengabdian kepada masyarakat ini adalah paguyuban Kawargian Adat yang berada di kawasan objek wisata budaya Ciung Wanara Desa Karangkamulyan Kecamatan Cijeunging Kabupaten Ciamis, khususnya para petugas parkir. Untuk menunjang kegiatan pengabdian kepada masyarakat, khalayak sasaran yang dipilih adalah para petugas parkir 
Pelatihan English Questions Bagi Para Petugas Parkir di Kawasan Wisata Budaya Ciung Wanara Karangkmulyan

Dedeh Rohayati, Andi Rustandi, Wawan Tarwana, Indah Nurkhasanah, Ade Rohana

yang berjumlah 6 orang di kawasan objek wisata budaya Ciung Wanara Desa Karangkamulyan Kecamatan Cijeungjing Kabupaten Ciamis. Mereka juga mempunyai kemauan untuk memiliki keterampilan bahasa Inggris mengenai English Questions berupa: 1) Kalimat tanya Bahasa Inggris jenis Yes/No Questions, dan 2) Kalimat tanya Bahasa Inggris menggunakan kata tanya $(5 \mathrm{~W}+1 \mathrm{H}$ Questions $)$. Pemilihan dan penetapan sasaran pelatihan ini mempunyai pertimbangan rasional-strategis dengan upaya pengentasan kemiskinan, dalam hal ini keterampilan menggunakan English Questions. Pengumpulan data diperoleh berdasarkan kerangka pikir untuk pemecahan masalah yang dipaparkan dalam Tabel 1.

Table 1. Kerangka Pikir Untuk Pemecahan Masalah

\begin{tabular}{l|l}
\hline \multicolumn{1}{c|}{ Masalah } & \multicolumn{1}{c}{ Upaya Pemecahan Masalah } \\
\hline $\begin{array}{l}\text { Bagaimana pelaksanaan pembelajaran yang } \\
\text { tepat bagi khalayak sasaran seperti para } \\
\text { petugas parkir supaya memiliki kemauan dan } \\
\text { kemampuan komunikasi bahasa Inggris } \\
\text { menggunakan English Questions? }\end{array}$ & $\begin{array}{l}\text { Diisi ceramah, tanya jawab dan contoh kasus } \\
\text { dilandasi prinsip-prinsip pembelajaran kepada } \\
\text { orang dewasa (andragogik) }\end{array}$ \\
\hline $\begin{array}{l}\text { Bagaimana kemampuan para petugas parkir } \\
\text { mengenai English Questions, khususnya } \\
\text { mengenai: 1) Kalimat tanya Bahasa Inggris }\end{array}$ & $\begin{array}{l}\text { Dilakukan survey pada tahap persiapan dan } \\
\text { setelah pelatihan English Questions, yang } \\
\text { terdiri atas: (1) Kalimat tanya Bahasa Inggris }\end{array}$ \\
$\begin{array}{l}\text { jenis Yes/ No Questions, dan 2) Kalimat tanya } \\
\text { Bahasa Inggris menggunakan kata tanya } \\
\text { (5W+1H Questions) }\end{array}$ & $\begin{array}{l}\text { jenis Yes/ No Questions, dan 2) Kalimat tanya } \\
\text { Bahasa Inggris menggunakan kata tanya } \\
\text { (5W+1H Questions), dilakukan ujian atau } \\
\text { penilaian. }\end{array}$ \\
\hline $\begin{array}{l}\text { Bagaimana implementasi pelatihan mengenai } \\
\text { English Questions - "Kalimat tanya Bahasa } \\
\text { Inggris dengan jawaban Ya/Tidak", dan }\end{array}$ & $\begin{array}{l}\text { Selain pembelajaran learning by doing dan } \\
\text { dilakukan di luar kelas (outdoor learning } \\
\text { learning); yaitu latihan dilakukan pada saat } \\
\text { "Kalimat tanya Bahasa Inggris menggunakan } \\
\text { kata tanya (5W+1HQuestions)"- terhadap para } \\
\text { petugas parkir di kawasan objek wisata budaya } \\
\text { Ciung Wanara Karangkamulyan? }\end{array}$ \\
$\begin{array}{l}\text { petugas parkir secarakelompok dan individual, } \\
\text { metode project-based learning juga diterapkan } \\
\text { dalam pelatihan ini, yang dilandasi prinsip } \\
\text { pembelajaran kepada orang dewasa } \\
\text { (andragogik). }\end{array}$ \\
\hline
\end{tabular}

Sumber: Data Primer (2020)

Seperti dijelaskan sebelumnya, kegiatan ini diberikan kepada orang dewasa sehingga bentuk pelatihan digunakan dalam kegiatan pengabdian kepada masyarakat ini. Berkaitan dengan tahapan pelatihan, kegiatan ini terdiri atas beberapa tahapan, diantaranya: 1) Tahap Persiapan yang meliputi survey, pemantapan dan penentuan lokasi dan sasaran, dan penyusunan bahan/materi pelatihan, yang meliputi: makalah dan modul untuk kegiatan pelatihan bahasa Inggris kepada para petugs parkir di kawasan objek wisata budaya Ciung Wanara; 2) Tahap Pelaksanaan Pelatihan mengenai penjelasan tentang pelatihan English Questions yang meliputi: 1) Kalimat tanya Bahasa Inggris jenis Yes/No Questions, dan 2) Kalimat tanya Bahasa Inggris menggunakan kata tanya $(5 \mathrm{~W}+1 \mathrm{H}$ Questions yang 
berhubungan dengan dunia pekerjaannya; dan 3) Tahap pelatihan secara individu, dimana para petugas parkir mendapat pengetahuan secara langsung sambil melakukan aktifitasnya sebagai juru parkir.

Dalam pelaksanaannya, metode pembelajaran berbasis proyek (Project-based Learning) diterapkan, yang dapat dilihat dalam proses pelatihan. Langkah-langkah dalam pembelajaran berbasis proyek diantaranya: 1) Metode Ceramah untuk memberikan penjelasan tentang English Questions; 2) Metode Tanya Jawab yang sangat penting bagi para peserta pelatihan untuk membahas materi English Questions; 3) Metode Modelling yang bertujuan untuk memberikan contoh pengetahuan mengenai cara pengucapan dan penggunaan intonasi yang benar mengenai English Questions; dan 4) Rancangan Evaluasi yang dilakukan selama proses dan di akhir pelatihan.

Tekhnik pengumpulan data kegiatan pengabdian kepada masyarakat ini diperoleh melalui observasi dan dokumentasi video. Data tersebut kemudian dianalisis dengan berbagai teori yang mendukung topik dalam pengabdian ini. Sedangkan hasil evaluasi kemampuan English Questions di analisis menggunaan rubrik penilaian CEFR (Common European Framework of Reference for Languages). Hasil analisis data pengabdian kemudian ditampilkan dalam bentuk tabel.

\section{HASIL DAN PEMBAHASAN}

\section{Prinsip Pembelajaran Orang Dewasa pada Pelatihan English Questions kepada Para Petugas Parkir}

Seperti dikemukakan sebelumnya, pengabdian kepada masyarakat ini dilakukan di kawasan wisata budaya Ciung Wanara, Karangkamulyan, Kecamatan Cijeungjing, Kabupaten Ciamis. Kegiatan yang berlangsung selama satu bulan di era New Normal ini dilaksanakan setiap hari Senin di akhir bulan Juni sampai bulan Juli 2020. Adapun bentuk kegiatan berupa pelatihan English Questions kepada para petugas parkir yang berjumlah 6 orang. Selain itu, pelaksanaan pelatihan ini sangat memegang prinsip pembelajaran orang dewasa yang diadaptasi dari Knowles (2005); dan Brown (2007) mengenai prinsip pembelajaran bahasa pada orang dewasa.

Sebelum pelaksanaan pelatihan, peserta pelatihan dilibatkan dalam perencanaan dan penentuan tujuan pembelajaran serta jadwal pelatihan. Sehingga pertemuan dilakukan secara tatap muka mencapai 7 kali pertemuan, dan sisanya penugasan terstruktur, dan kegiatan mandiri tidak terstruktur sehingga total 10 kali pertemuan. Ketiga jenis pertemuan ini sangat sesuai untuk peserta pelatihan yang secara demografis, merupakan pembelajar 
Pelatihan English Questions Bagi Para Petugas Parkir di Kawasan Wisata Budaya Ciung Wanara Karangkmulyan

Dedeh Rohayati, Andi Rustandi, Wawan Tarwana, Indah Nurkhasanah, Ade Rohana

orang dewasa yang berusia di atas 25 tahun dan bekerja sebagai petugas parkir. Keuntungan lain dari ketiga jenis pertemuan pembelajaran ini adalah bahwa peserta pelatihan memiliki konsentrasi yang lebih lama dibanding anak-anak; dan tidak terlalu banyak memerlukan variasi selama pelatihan berlangsung (Brown, 2007).

Berkaitan dengan tujuan pembelajaran, mereka menginginkan pembelajaran lebih fokus kepada kemampuan berkomunikasi atau language skill. Maka, materi dikhususkan kepada kemampuan berbicara menggunakan English Questions. Dengan demikian, kemampuan grammar atau tata bahasa tidak terlalu penting bagi mereka. Setelah sepakat mengenai tujuan pembelajaran, jadwal pelatihan pun dilakukan tanpa mengganggu aktifitas pekerjaan mereka. Oleh karena itu, pelatihan disesuaikan dengan jadwal pekerjaan mereka yaitu dilaksanakan setiap hari Senin setelah salat Asar sampai menjelang salat Magrib.

Penentuan tujuan dan jadwal pelatihan tersebut di atas tentu saja dilandasi oleh pengalaman sebagai asas aktivitas pembelajaran. Disamping pengalaman pekerjaan, mereka telah memiliki pengalaman belajar Bahasa Inggris sebelumnya; dan bahkan mereka sudah memiliki pengalaman menghadapi turis asing dan berkomunikasi langsung dalam Bahasa Inggris yang sangat terbatas. Pengalaman-pengalaman tersebut menjadi penunjang aktifitas pembelajaran mereka selama pelatihan English Questions.

Pelatihan ini juga berpegang pada dua prinsip penting Knowles (2005) lainnya, yaitu pembelajaran diarahkan pada materi English Questions yang berkaitan langsung dengan pekerjaan mereka; dan dorongan motivasi yang tinggi serta pemecahan masalah. Materi English questions diarahkan pada berbagai situasi bahasa seperti: 1) saat turis datang atau turun dari bus di area parkir; 2) ketika turis hendak mencari restoran; 3) ketika turis keluar dari restoran; 4) saat turis memasuki area objek wisata budaya Ciung Wanara Karangkamulyan; 5) ketika turis keluar dari area situs; dan 6) saat turis akan segera melanjutkan perjalanan. Pemahaman mereka terhadap berbagai situasi bahasa sangat tinggi karena faktor usia menjadikan mereka memahami hal-hal yang abstrak dengan mudah.

Sedangkan dorongan motivasi memungkinkan mereka untuk tetap semangat selama pelatihan berlangsung dan dapat memecahkan masalah dalam pengucapan Bahasa Inggris yang baik dan benar. Mereka mengakui bahwa aspek pelafalan atau pengucapan menjadi kendala saat berbicara Bahasa Inggris. Namun, dengan semangat yang tinggi dan ditunjang oleh rasa percaya diri, mereka mampu mengikuti pelatihan English Questions dengan antusias. Oleh karena itu, tim pelaksana melakukan modelling (pemberian contoh) dan repetition (pengulangan) terhadap materi English Questions dengan pengucapan atau pelafalan yang baik dan benar. 
Berdasarkan uraian tersebut di atas, pelaksanaan pengabdian kepada masyarakat ini telah berhasil dengan baik sesuai tujuan yang diharapkan. Alasannya adalah penerapan prinsip-prinsip pembelajaran kepada orang dewasa dan pembelajaran bahasa bagi orang dewasa telah diintegrasikan dengan maksimal. Peserta pelatihan yang terdiri atas para petugas memiliki kemauan untuk mengikuti pelatihan sehingga mampu berkomunikasi dengan baik dengan menggunakan English Questions. Dengan demikian, pelaksanaan pengabdian secara umum harus merujuk kepada prinsip-prinsip diatas apabila khalayak sasaran terdiri atas masyarakat berusia dewasa dan sudah bekerja seperti yang telah dilakukan oleh Rustandi, dkk. (2019) serta Febriani, dkk. (2019) walaupun memiliki topik pelatihan Bahsa Inggris yang berbeda.

\section{Implementasi Pembelajaran Berbasis Proyek pada Pelatihan English Questions kepada Para Petugas Parkir}

Tekad yng begitu kuat dalam diri peserta pelatihan untuk memiliki kemauan mengikuti pelatihan English Questions tidak mungkin berhasil tanpa didukung metode pembelajaran yang tepat. Salah satu metode pembelajaran yang sesuai dalam kegiatan pengabdian kepada masyarakat ini adalah pembelajaran berbasis proyek. Oleh karena itu, implementasi pembelajaran berbasis proyek pada pelatihan English Questions kepada para petugas parkir dipaparkan pada paragraf selanjutnya.

Seperti dsampaikan oleh beberapa ahli (Patton, 2012; Holm, 2011), pembelajaran berbasis proyek merujuk kepada pelaksanaan proyek dalam jangka waktu yang panjang untuk mempamerkan output, dalam kasus ini adalah kemampuan menggunakan English Questions. Dalam pelatihan ini, pelaksana pengabdian kepada masyarakat berperan sebagai fasilitator yang menyediakan bimbingan dan instruksi strategis, serta sebagai penasehat dan koordinator (Patton, 2012; Wright, 2011; Fragoulis, 2009).

Selain kehadiran seorang fasilitator, materi atau isi kurikulum menjadi pusat pembelajaran. Materi yang dimaksud dalam kegiatan pengabdian kepada masyarakat ini adalah English Questions. Hal menonjol lainnya dalam pembelajaran berbasis proyek adalah students centered learning; artinya peserta pelatihan dituntut untuk belajar secara mandiri dan mampu mengembangan ide-ide untuk menuntaskan masalah (seperti kesulitan dalam pengucapan ungkapan Bahasa Inggris) yang ada dalam kehidupan sehari-hari. Oleh sebab itu, mereka diberikan kesempatan untuk melakukan belajar mandiri dalam penugasan terstruktur, dan kegiatan mandiri tidak terstruktur. 
Kegiatan pelatihan ini juga memiliki karakteristik metode pembelajaran berbasis proyek yang dikemukanan oleh Klein (2009) dan Bas \& Beyhan (2010), yakni, mengutamakan minat dan kebutuhan pemelajar. Disamping itu, pelatihan ini telah dilakukan secara maksimal karena disertai modelling yang diperankan langsung oleh ketua pelaksana, anggota, dan pembantu anggota pelaksana, atau murid sebaya seperti yang disarankan oleh Walqui (2006).

Sedangkan tahapan metode pembelajaran berbasis proyek yang merujuk kepada Bell (2010) dan Fragoulis (2009) dapat dilihat dalam Tabel 2.

Tabel 2. Realisasi Kegiatan Pembelajaran Berbasis Proyek

\begin{tabular}{|c|c|c|c|}
\hline Minggu & $\begin{array}{c}\text { Hari/ } \\
\text { Tanggal }\end{array}$ & Uraian & Keterangan \\
\hline 1. & $\begin{array}{l}\text { Jumat, } \\
26 \text { Juni } \\
2020\end{array}$ & $\begin{array}{l}\text { Diskusi bersama mengenai kemampuan Bahasa Inggris } \\
\text { yang dimiliki para petugas parkir, tantangan dan } \\
\text { solusinya, rencana, dan jadwal pelatihan }\end{array}$ & $\begin{array}{l}\text { Masalah: } \\
\text { kemampuan } \\
\text { menggunakan } \\
\text { Bahasa Inggris } \\
\text { yang rendah }\end{array}$ \\
\hline 2. & $\begin{array}{l}\text { Sabtu, } \\
27 \text { Juni } \\
2020\end{array}$ & $\begin{array}{l}\text { Pemberian motivasi kepada para peserta pengabdian } \\
\text { dan perencanaan pelatihan English Questions }\end{array}$ & $\begin{array}{l}\text { Masalah: } \\
\text { motivsi dan } \\
\text { antusiasme yang } \\
\text { masih rendah }\end{array}$ \\
\hline 3. & $\begin{array}{l}\text { Senin, } \\
29 \text { Juni } \\
2020\end{array}$ & $\begin{array}{l}\text { - Pemaparan materi Pelatihan English Questions } \\
\text { meliputi penjelasan tentang Yes-No Questions dan } \\
5 W+1 H \text { Questions } \\
\text { - Pemberian contoh (modelling) pengucapan Yes-No } \\
\text { Questions dan } 5 W H \text { questions yang baik dan benar } \\
\text { kemudian diulangi (repetition) oleh para petugas } \\
\text { parkir. } \\
\text { - Pemaparan materi Yes-No Questions dan } 5 W+1 H \\
\text { Questions dalam percakapan yang digunakan oleh } \\
\text { para petugas parkir di kawasan objek wisata budaya } \\
\text { Ciung Wanara Karangkamulyan diantaranya } \\
\text { bagaimana bertanya 1) saat turis datang atau } \\
\text { turun dari bus (area parkir); 2) ketika turis ingin } \\
\text { mencari restoran; 3) ketika turis keluar dari } \\
\text { restoran; 4) saat turis memasuki area Ciung } \\
\text { Wanara Karangkmulyan; 5) ketika turis keluar } \\
\text { dari area situs; dan 6) saat turis akan segera } \\
\text { melanjutkan perjalanan. }\end{array}$ & $\begin{array}{l}\text { Masalah: } \\
\text { Pronounciation }\end{array}$ \\
\hline 4. & $\begin{array}{l}\text { Senin, } 6 \\
\text { Juli } \\
2020\end{array}$ & $\begin{array}{l}\text { - Pemaparan materi dan penjelasan mengenai } \\
\text { Pertanyaan saat turis datang atau turun dari bus } \\
\text { (area parkir); dan Pertanyaan ketika turis ingin } \\
\text { mencari restoran. } \\
\text { - Tutor melakukan modelling, yakni dengan } \\
\text { mengucapkan ungkapan-ungkapan Bahasa Inggris } \\
\text { tersebut dengan benar, kemudian diulangi } \\
\text { (repetition) oleh para petugas parkir. } \\
\text { - Para petugas parkir diminta untuk melakukan dialog } \\
\text { dan tanya jawab satu persatu, yang pertama } \\
\text { melakukan tanya jawab dengan Tutor, yang kedua } \\
\text { melakukan tanya jawab dengan sesama petugas }\end{array}$ & $\begin{array}{l}\text { Masalah: } \\
\text { Pronounciation }\end{array}$ \\
\hline
\end{tabular}




\begin{tabular}{|c|c|c|c|}
\hline & & $\begin{array}{l}\text { parkir. } \\
\text { Kegiatan diakhiri dengan praktek melakukan } \\
\text { percakapan secara berpasangan. Dari kegiatan ini } \\
\text { mereka nampak antusias dan interaktif. Dapat } \\
\text { disimpulkan bahwa mereka memiliki motivasi yang } \\
\text { tinggi dalam pelatihan ini. }\end{array}$ & \\
\hline 5. & $\begin{array}{l}\text { Senin, } \\
13 \text { Juli } \\
2020\end{array}$ & $\begin{array}{l}\text { - Pemaparan materi dan penjelasan mengenai } \\
\text { Pertanyaan ketika turis keluar dari restoran; } \\
\text { dan Pertanyaan saat turis memasuki area Ciung } \\
\text { Wanara Karangkamulyan } \\
\text { - Tutor melakukan modelling, yakni dengan cara } \\
\text { mengucapkan ungkapan-ungkapan Bahasa Inggris } \\
\text { tersebut dengan benar, kemudian diulangi } \\
\text { (repetetion) oleh para petugas parkir. } \\
\text { - Para petugas parkir diminta untuk melakukan dialog } \\
\text { dan tanya jawab satu persatu. Yang pertama } \\
\text { melakukan tanya jawab dengan Tutor, yang kedua } \\
\text { melakukan tanya jawab dengan sesama petugas } \\
\text { parkir. Dalam tahap ini tutor memberikan tambahan } \\
\text { kosakata. Oleh karena itu, pada pertemuan ini, para } \\
\text { petugas parkir semakin aktif berbicara Bahasa } \\
\text { Inggris menggunakan beberapa kosakata Bahasa } \\
\text { Inggris dalam tindak tutur merespon, memberikan } \\
\text { opini, dan alasan Bahasa yang lain, seperti great, } \\
\text { nice, wonderful, fantastic, beautiful, No, thanks, I } \\
\text { am full, sure, dan of course. Dengan demikian, } \\
\text { mereka telah menunjukan kemampuan komunikasi } \\
\text { dua arah secara berterima } \\
\text { - Kegiatan diakhiri dengan praktek melakukan } \\
\text { percakapan secara berpasangan; dari kegiatan ini } \\
\text { mereka nampak antusias dan interaktif. Dapat } \\
\text { disimpulkan bahwa mereka memiliki motivasi yang } \\
\text { tinggi dalam pelatihan ini. }\end{array}$ & $\begin{array}{l}\text { Masalah: } \\
\text { Pronounciation }\end{array}$ \\
\hline 6. & $\begin{array}{l}\text { Senin, } \\
20 \text { Juli } \\
2020\end{array}$ & $\begin{array}{l}\text { - Pemaparan materi dan penjelasan mengenai } \\
\text { Pertanyaan ketika turis keluar dari area situs; } \\
\text { dan Pertanyaan saat turis akan segera } \\
\text { melanjutkan perjalanan. } \\
\text { - Tutor melakukan modelling, yakni dengan cara } \\
\text { mengucapkan ungkapan-ungkapan Bahasa Inggris } \\
\text { tersebut dengan benar, kemudian diulangi } \\
\text { (repetition) oleh para petugas parkir. } \\
\text { - Kegiatan diakhiri dengan praktek melakukan } \\
\text { percakapan secara berpasangan; dari kegiatan ini } \\
\text { mereka nampak antusias dan interaktif. Dapat } \\
\text { disimpulkan bahwa mereka memiliki motivasi yang } \\
\text { tinggi dalam pelatihan ini. Tak hanya itu, mereka } \\
\text { semakin percaya diri saat melakukan dialog yang } \\
\text { dibuktikan dengan adanya penambahan penggunaan } \\
\text { kosakata lain seperti escourt, dan menggunakan } \\
\text { ungkapan seperti... and the distance from here to } \\
\text { Jogjakarta is about } 100 \text { km and it's about three } \\
\text { hours. }\end{array}$ & $\begin{array}{l}\text { Masalah: } \\
\text { Pronounciation }\end{array}$ \\
\hline 7. & $\begin{array}{l}\text { Senin, } \\
27 \quad \text { Juli } \\
2020\end{array}$ & $\begin{array}{l}\text { Ujian: Buatlah sebuah dialog menggunakan } 5 \\
\text { pertanyaan, minimal, @ satu (1) Pertanyaan saat turis } \\
\text { datang atau turun dari bus di area parkir; satu (1) }\end{array}$ & Jenis test: Lisan \\
\hline
\end{tabular}




\begin{tabular}{l|l|l}
\hline & $\begin{array}{l}\text { Pertanyaan ketika turis hendak mencari restoran; satu } \\
\text { (1) Pertanyaan ketika turis keluar dari restoran; satu } \\
\text { (1) Pertanyaan saat turis memasuki area Ciung } \\
\text { Wanara; satu (1) Pertanyaan ketika turis keluar dari } \\
\text { area situs; dan satu (1) Pertanyaan saat turis akan } \\
\text { segera melanjutkan perjalanan. }\end{array}$ \\
\hline
\end{tabular}

Sumber: Analisis Data Primer (2020)

Tabel 2 di atas menggambarkan implementasi pembelajaran berbasis proyek yang diawali dengan mengidentifikasi masalah diantaranya rendahnya kemampuan menggunakan bahasa Inggris sesuai dengan bidang pekerjaannya, dan pronounciation. Setelah itu, dilakukan perencanaan jadwal pembelajaran pada akhir bulan Juni 2020. Kemudian pelaksanaan pelatihan English Questions yang dilakukan pada bulan Juli 2020 setiap hari Senin mulai jam 15.30 sampai dengan pukul 17.00 WIB. Pertemuan tatap muka sebanyak 4 kali (Pertemuan 3, 4, 5, dan 6), dan sisanya adalah penugasan terstruktur, dan kegiatan mandiri tidak terstruktur. Pertemuan ke 7 merupakan tahapan terakhir dari pembelajaran berbasis proyek yaitu ujian lisan yang dinilai secara deskriptif berdasarkan CEFR (Common European Framework of Reference for Languages). Pola pelaksanaan ini tentu saja berbeda dengan pengabdian yang dilakukan oleh Permata dan Hadiyani (2018) yang memilih khalayak sasaran mahasiswa Bidikmisi Polman Bandung; serta didukung pre-test dan post test sebagai instrumen pengumpulan datanya. Namun, memiliki kesamaan tujuan yakni untuk meningkatkan daya saing.

\section{Hasil Evaluasi Pelatihan English Questions kepada Para Petugas Parkir}

Tahapan terakhir dari kegiatan ini adalah penilaian atau evaluasi, yakni, penilaian terhadap kemampuan para petugas parkir dalam menggunakan English Questions dan penilaian terhadap kegiatan tersebut. Penilaian kemampuan menggunakan English Questions merujuk kepada CEFR (Common European Framework of Reference for Languages).

Adapun hasil penilaian pelatihan berdasarkann CEFR menunjukan bahwa, kemampuan para petugas parkir termasuk kategori A1, yaitu tingkat dasar atau elementary. Menurut kategori A1, para petugas parkir mampu berinteraksi secara lisan (Overall Spoken Interaction), yaitu, mengungkapkan pertanyaan yang sederhana (Can ask simple questions). Kemampuan yang dimiliki 6 peserta pengabdian tersebut diuraikan secara rinci dalam Tabel 3, 4, 5, 6, 7, 8 . 
Tabel 3. English Questions Peserta 1

\begin{tabular}{l|l}
\multicolumn{1}{c|}{ Situasi Bahasa } & \multicolumn{1}{c}{ English Questions } \\
\hline 1) Saat turis datang atau turun dari bus (area parkir) & Do you speak English? \\
\hline 2) Pertanyaan ketika turis ingin mencari restoran & Do you want to drink? \\
\hline 3) Ketika turis keluar dari restoran & Do you like the food? \\
\hline 4) Saat turis memasuki area Ciung Wanara & How many ticket will you buy? \\
\hline 5) Ketika turis keluar dari area situs & Do you like the athmosphere? \\
\hline 6) Saat turis akan segera melanjutkan perjalanan & $\begin{array}{l}\text { Are going to Pangandaran } \\
\text { Is that your bus? }\end{array}$ \\
\hline
\end{tabular}

Sumber: Analisis Data Primer (2020)

Tabel 3 menunjukan kemampuan peserta menggunakan English Questions dengan sempurna, walaupun hanya satu saja dari setiap situasi bahasa. Kecuali situasi Bahasa yang ke-enam, peserta mampu menampilkan dua English Questions. Secara demografis, usia Peserta 1 adalah di atas 50 tahun.

Tabel 4. English Questions Peserta 2

\begin{tabular}{l|l}
\multicolumn{1}{c}{ Situasi Bahasa } & \multicolumn{1}{c}{ English Questions } \\
\hline 1) Saat turis datang atau turun dari bus (area parkir) & Do you speak English? \\
\hline 2) Pertanyaan ketika turis ingin mencari restoran & $\begin{array}{l}\text { Have you some food? } \\
\text { Do you want to have some food? }\end{array}$ \\
\hline 3) Ketika turis keluar dari restoran & $\begin{array}{l}\text { Do you like the food? } \\
\text { How do you feel? }\end{array}$ \\
\hline 4) Saat turis memasuki area Ciung Wanara & Do you want ticket? \\
\hline 5) Ketika turis keluar dari area situs & $\begin{array}{l}\text { How was your travelling? } \\
\text { Did you see the monkey? } \\
\text { Have you finished the travelling? }\end{array}$ \\
\hline 6) Saat turis akan segera melanjutkan perjalanan & $\begin{array}{l}\text { Are you going to Pangandaran now? } \\
\text { Is that your bus? }\end{array}$ \\
\hline
\end{tabular}
Sumber: Analisis Data Primer (2020)

Tidak seperti Tabel 3, Tabel 4 menunjukan kemampuan Peserta 2 menggunakan English Questions yang lebih bervariasi. Hal ini disebabkan karena usia Peserta 2 di bawah 20 tahun. Akibatnya dia mampu menghafal lebih banyak English Questions dengan baik dan benar. Dengan demikian, Peserta 2 berhak menjadi peserta terbaik dalam pelatihan English Questions ini.

Tabel 5. English Questions Peserta 3

\begin{tabular}{l|l}
\multicolumn{1}{c}{ Situasi Bahasa } & \multicolumn{1}{c}{ English Questions } \\
\hline 1) Saat turis datang atau turun dari bus (area parkir) & Do you speak English? \\
\hline 2) Pertanyaan ketika turis ingin mencari restoran & Are you looking for the restaurant? \\
\hline 3) Ketika turis keluar dari restoran & How do you like our food? \\
\hline 4) Saat turis memasuki area Ciung Wanara & Do you need a guide? \\
\hline 5) Ketika turis keluar dari area situs & $\begin{array}{l}\text { Did you see any monkey? } \\
\text { Did you feed one of them? }\end{array}$ \\
\hline 6) Saat turis akan segera melanjutkan perjalanan & Which one is your bus? \\
\hline
\end{tabular}


Tabel 5 hampir sama dengan Tabel 4, yakni, Peserta 3 hanya mampu menggunakan satu English Questions dari setiap situasi bahasa, kecuali untuk situasi bahasa ke-5. Namun demikian, Peserta 4 mampu menampilkan kosakata baru yang tidak terdapat dalam modul yang diberikan TIM pengabdian kepada masyarakat sebelumnya. Kosakata tersebut yaitu need.

Tabel 6 English Questions Peserta 4

\begin{tabular}{l|l}
\multicolumn{1}{c|}{ Situasi Bahasa } & \multicolumn{1}{c}{ English Questions } \\
\hline 1) Saat turis datang atau turun dari bus (area parkir) & Can you speak English? \\
\hline 2) Pertanyaan ketika turis ingin mencari restoran & Are you looking for restaurant? \\
\hline 3) Ketika turis keluar dari restoran & Have you taken some food? \\
\hline 4) Saat turis memasuki area Ciung Wanara & Will you get in the area? \\
\hline 5) Ketika turis keluar dari area situs & How was your travelling? \\
\hline 6) Saat turis akan segera melanjutkan perjalanan & Is this your bus? \\
\hline
\end{tabular}

$$
\text { Sumber: Analisis Data Primer (2020) }
$$

Tabel 6 menunjukan kemampuan menggunakan English Questions yang dimiliki Peserta 4 sama dengan kemampuan Peserta 6 dalam menggunakan English Questions. Kemampuan ini akibat dari kemauan dan motivasi yang tinggi untuk mempelajari Bahasa Inggris khususnya menggunakan English Questions.

Tabel 7 English Questions Peserta 5

\begin{tabular}{l|l}
\multicolumn{1}{c|}{ Situasi Bahasa } & \multicolumn{1}{c}{ English Questions } \\
\hline 1) Saat turis datang atau turun dari bus (area parkir) & Do you speak English? \\
\hline 2) Pertanyaan ketika turis ingin mencari restoran & Do you want to have some food? \\
\hline 3) Ketika turis keluar dari restoran & Do you like the food? \\
\hline 4) Saat turis memasuki area Ciung Wanara & Will you get in Ciung Wanara area? \\
\hline 5) Ketika turis keluar dari area situs & - \\
\hline 6) Saat turis akan segera melanjutkan perjalanan & - \\
\hline
\end{tabular}

\section{Sumber: Analisis Data Primer (2020)}

Tabel 7 menunjukan kemampuan yang mencolok karena Peserta 5 hanya mampu menampilkan English Question untuk 4 situasi bahasa. Sedangkan untuk situasi bahasa yang ke-5 dan ke-6, Peserta 5 tidak memiliki kemampuan menampilkan English Questions karena memiliki motivasi yang tidak maksimal. Peserta 5 merupakan kategori poor students pada pelatihan English Questions ini. English Questions Peserta 6 dapat dilihat pada Tabel 8 .

Tabel 8 menunjukan kemampuan Peserta 6 yang lebih baik dibanding Peserta 5 . Peserta 6 mampu menampilkan satu English Questions untuk semua situasi bahasa. Kemampuan Peserta 6 sepadan dengan kemampuan yang dimiliki Peserta 4. 
Tabel 8 English Questions Peserta 6

\begin{tabular}{l|l}
\multicolumn{1}{c|}{ Situasi Bahasa } & \multicolumn{1}{c}{ English Questions } \\
\hline 1) Saat turis datang atau turun dari bus (area parkir) & Are you going to the toilet? \\
\hline 2) Pertanyaan ketika turis ingin mencari restoran & Do you want to have some food? \\
\hline 3) Ketika turis keluar dari restoran & Do you like the food? \\
\hline 4) Saat turis memasuki area Ciung Wanara & Will you visit the situs? \\
\hline 5) Ketika turis keluar dari area situs & How was your travelling? \\
\hline 6) Saat turis akan segera melanjutkan perjalanan & How was your travelling? \\
\hline
\end{tabular}

Sumber: Analisis Data Primer (2020)

Berdasarkan hasil evaluasi di atas, peningkatan kemampuan English Questions para petuugas parkir pada dasarnya didorong oleh motivasi yang kuat serta kepercyaan diri mereka. Hal ini berlaku untuk semua pelatihan Bahasa Inggris untuk jenis dan topik apapun seperti pengabdian pelatihan pelafalan kosakata Bahas Inggris bidang peternakan yang telah dilakukan oleh Ariyani, dkk. (2014).

\section{KESIMPULAN DAN REKOMENDASI}

\section{Kesimpulan}

Dengan merujuk kepada hasil dan pembahasan, beberapa hal penting dapat disimpulkan diantaranya adalah sebagai berikut:

Pertama, pelaksanaan pelatihan English Questions dapat terlaksana dengan baik dengan mempertimbangkan prinsip-prinsip pembelajaran kepada orang dewasa. Yang lebih penting lagi, prinsip-prinsip khusus pembelajaran bahasa bagi orang dewasa telah disinergikan dengan baik. Kedua prinsip-prinsip tersebut di atas dapat menumbuhkan motivasi peserta pelatihan yang beranggotakan para petugas parkir di kawasan wisata budaya Ciung Wanara, Desa Karangkmulyan, Kecamatan Cijeungjing, Kabupaten Ciamis. Mereka, para peserta pelatihan adalah .khalayak yang memiliki kemauan keras untuk belajar berkomunikasi menggunakan bahasa Inggris, khususnya mengenai English Questions.

Kedua, kegiatan pengabdian telah berkontribusi kepada para petugas parkir dikawasan Wisata Budaya Ciung Wanara, Desa Karangkmulyan, Kecamatan Cijeungjing, Kabupaten Ciamis, sehingga mereka mampu berkomunikasi menggunakan English Questions. Kemampun tersebut diantaranya menggunakan English Questions untuk berbagai situasi seperti pertanyaan (1) saat turis datang atau turun dari bus di area parkir; (2) ketika turis hendak mencari restoran; (3) ketika turis keluar dari restoran; (4) saat turis memasuki area Ciung Wanara Karangkamulyan; (5) ketika turis keluar dari area situs; dan (6) saat turis akan segera melanjutkan perjalanan. 
Pelatihan English Questions Bagi Para Petugas Parkir di Kawasan Wisata Budaya Ciung Wanara Karangkmulyan

\section{Rekomendasi}

Pertama, untuk pelaksana pengabdian, disarankan dapat mengembangkan area pengabdian yang lebih luas (dengan topik yang sama) baik dari aspek metodologi dan materinya. Diharapkan juga untuk pengabdian mendatang, sasaran khalayak berasal dari unsur-unsur lain yang ada di kawasan wisata budaya Ciung Wanara Karangkamulyan, Kecamatan Cijeungjing Kabupaten Ciamis, termasuk anggota keluarga para petugas parkir itu sendiri.

Kedua, untuk para petugas parkir, disarankan untuk tetap berlatih berkomunikasi Bahasa Inggris, khususnya menggunakan English Questions. Juga, mereka harus terus berupaya meningkatkan ilmu pengetahuan tersebut dengan mencari akses terhadap pengajaran komunikasi Bahasa Inggris.

Ketiga, untuk instansi terkait disarankan memberikan perhatian yang besar kepada para petugas parkir dengan mempermudah akses mendapatkan pelatihan komunikasi Bahasa Inggris unntuk menunjang bidang pekerjaannya sekaligus meningkatkan daya saing.

\section{UCAPAN TERIMA KASIH}

Tim pengabdian kepada masyarakat mengucapkan terima kasih kepada Rektor Universitas Galuh dan Ketua LPPM Universitas Galuh yang telah mendanai kegiatan pengabdian kepada masyarakat ini sehingga pelaksanaan berjalan dengan baik. Disamping itu, kami juga mengucapkan terimakasih kepada paguyuban Kawargian Adat khususnya para petugas parkir, di kawasan wisata budaya Ciung Wanara Desa Karangkamuyan Kecamatan Cijeunging Kabupaten Ciamis Jawa Barat, serta pihak-pihak terkait yang telah membantu terlaksananya kegiatan ini.

\section{DAFTAR PUSTAKA}

Aryani, I G.AG. I., Oka, I G. L.,Wibawa, A.A.P.P., Warmadewi, D. A., dan Trisnadewi, A.A.A. S. (2014). Pelafalan kosakata bahasa Inggris bidang peternakan masyarakat di desa pengotan. Udayana Mengabdi, 13(1), Tahun 2014.

Bas, G \& Beyhan, O. (2010). Effects of multiple intelligence supported project-based learning in Students' Achievement Levels and Attitude towards English Lesson. International Elekronik Journal of Elementary Education. 02 (03), 365-386.

Bell, S. (2010). Project-based learning for the 21st century: skills for the future, Interdiciplinar Journal of Project-Based Learning, 83 (02), 39-43, DOI: 10.1080/00098650903505415.

Brown, H. 2007. Principles of Language Learning and Teaching. NY: Pearson Education Inc. 
Dudley-Evans, T. and St. Jhon, M.J. (1998). Developments in English for specific purposes: a multi-disciplinary approach. Cambridge University Press.

Eggins, S. (2004). An Introduction to Systemic Funnctional Linguistics. London: Continuum International Publishing Group.

Febriani, R. B., Rustandi, A., dan Sugiarto, B.R. (2019). Meningkatkan kemampuan bahasa Inggris anak dan remaja pra-sejahtera untuk mendukung kegiatan pariwisata situ Lengkong Panjalu. ABDIMAS GALUH, 1(1), (2019).

Fragoulis, L. (2009). Project-based learning in teaching of English as a foreign language in Greek primary school: from theory to practice. English language Teaching Journal, 02, (03), 113-119.

Hutchinson, T. and Waters, A. (1987). English for specific purpose. A learning-centered approach. Cambridge: Cambridge University Press. Diambil dari www.cambridge.org, (29 November 2016)

Holm, M. (2011). Project-based instruction : A review of the literature on effectiveness in prekindergarten through $12^{\text {nd }}$ grade classroom. Rivier Academic Journal. 07(02), 113.

Klein, J. I. et al. (2009). Project-based learning inspiring middle school student to engage in deep and active learning. New York: NYC Department of Education.

Knowles.M. (2005), The Adult Learner .LondonElsevier ButterWorth Heineman

Patton, A. (2012). Work that matters the teacher's guide to project-based learning. London: Paul Hamlyn Foundation.

Permata, N.N.,dan Hadiani, D. (2018). Pelatihan bahasa Inggris dasar dalam upaya peningkatan kemampuan mahasiswa bidikmisi polman Bandung. Jurnal Pengabdian Kepada Masyarakat Vol 2, No 4 (2018).

Rohayati, D., Herlina, R., dan Riyanto, B. (2019). Pelatihan Bahasa Inggris untuk paguyuban pedagang "Kawargian Adat" dengan metode Project-Based Learning. ABDIMAS GALUH Volume 1,No. 1, 1-7, 2019.

Rustandi, A., Febriani, R.,B., dan Sugiarto, B. R. (2019). Pemberdayaan ibu-ibu PKK melalui pelatihan English for business dan English for tourism di desa Sukaresik kecamatan Sindangkasih kabupaten Ciamis. ABDIMAS GALUHVol 1, No 1 (2019).

Wright, W. G. (2011). Student centered in higher education. International Journal of Teaching and Learning in Higher Education, 23 (03), 92-97.

https://peraturan.bpk.go.id/Home/Details/26995 